\title{
Cardiac Glycosides as Novel Modulators of Cancer Cell Survival ${ }^{+}$
}

\author{
Marc Diederich \\ College of Pharmacy, Seoul National University, Seoul 08826, Korea; marc.diederich@lbmcc.lu \\ + Presented at the 2nd International Conference on Natural Products for Cancer Prevention and Therapy, \\ Kayseri, Turkey, 8-11 November 2017.
}

Published: 17 November 2017

\begin{abstract}
Cardiac glycosides (CGs) were initially described as a cure for cardiovascular diseases. More recently a correlation between CG intake and anticancer activity was suggested, further validated by in vivo and in vitro preclinical research. Our recent findings demonstrate that CGs efficiently act on cancer cell proliferation and survival [1]. UNBS1450 is a hemi-synthetic cardenolide that exerts cytostatic and cytotoxic effects in leukemia and solid tumors at low micromolar concentrations. In leukemia, downregulation of Mcl-1 was observed after 4 hours of treatment in the absence of any effect at the transcriptional level. By generalizing our observations with cardenolides and bufadienolides of different plant and animal origins, we showed that Mcl1 can be considered as a universal target for CGs in cancer. Moreover, we demonstrated that Mcl-1 degradation is proteasome-dependent preceding apoptotic cell death. Furthermore, UNBS140 also triggers autophagy and mitophagy in solid tumors like neuroblastoma. So far, UNBS1450 was shown to trigger both complete and incomplete mitophagy in neuroblastoma leading to necroptosis and apoptosis, respectively [2], depending on the subtype of neuroblastoma. In AML, a combination of UNBS1450 and BH3 mimetics like ABT199 or 263 affects leukemia subtypes relying on Mcl-1 expression [3]. Altogether CGs are interesting pharmacological agents that efficiently induce cell death in cancer cell models at nanomolar concentrations encouraging us to further explore the therapeutic potential for CGs alone or in combination with other targeted treatments.
\end{abstract}

Conflicts of Interest: The authors declare no conflict of interest.

\section{References}

1. Diederich, M.; Muller, F.; Cerella, C. Cardiac glycosides: From molecular targets to immunogenic cell death. Biochem. Pharmacol. 2016, 125, 1-11.

2. Radogna, F.; Cerella, C.; Gaigneaux, A.; Christov, C.; Dicato, M.; Diederich, M. Cell type-dependent ROS and mitophagy response leads to apoptosis or necroptosis in neuroblastoma. Oncogene 2016, 35, 3839-3853.

3. Cerella, C.; Gaigneaux, A.; Mazumder, A.; Lee, J.Y.; Saland, E.; Radogna, F.; Farge, T.; Vergez, F.; Recher, C.; Sarry, J.E.; et al. Bcl-2 protein family expression pattern determines synergistic pro-apoptotic effects of BH3 mimetics with hemisynthetic cardiac glycoside UNBS1450 in acute myeloid leukemia. Leukemia 2017, 31, 755-759.

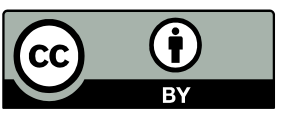

(C) 2017 by the authors. Licensee MDPI, Basel, Switzerland. This article is an open access article distributed under the terms and conditions of the Creative Commons Attribution (CC BY) license (http://creativecommons.org/licenses/by/4.0/). 